\title{
The Study of the Influence of Port Scale on Tugboat Configuration Based on System Simulation
}

\author{
Wenyuan Wang*, Tianqi Zheng and Yun Peng \\ Faculty of Infrastructure Engineering, Dalian University of Technology, Dalian, Liaoning, China \\ ${ }^{*}$ Corresponding author
}

\begin{abstract}
In the case of satisfactory waterway condition, the scale of the port area affects the tonnage and size of the vessels operated in the port directly, which leads to a higher demand on the tugboat configuration in the port. In this article, a simulation model of the operation system of ships entering and leaving the port is established based on the computer simulation technology to study the optimal quantity of tugboats required in the different handling capacity condition of the port. The result of the study shows that, in a certain range, the demand of the tugboats is increasing with the development of port handling capacity. However, when the handling capacity reaches a certain value, the increase of the tugboats number do not have a significantly effect on the improvement of port handling capacity.
\end{abstract}

Keywords—-throughput capacity; tugboat; system simulation

\section{INTRODUCTION}

With the continuous increase of port throughput and the trend of large-scale ships, the scale of the port area is constantly expanding, and the quantity of arriving ships is increasing as well, which leads to a higher demand on the tugboat configuration in the port. Tugboat operation is an indispensable part of the port production operation system. The tugboat assistance is required for berthing \& departing, making a U-turn and moving the mooring. The number and horsepower towing of the tugboats should be determined according to the tonnage and length of the ship appropriately. There would be a series of negative influences on the production and management of the port while the tug configuration is unreasonable.

In recent years, more and more attention has been paid to the research on tugboat configuration. And there has been some outcome and conclusion on the research of tug configuration. Dong Liangcai [1] established a mathematical model of tugboat dynamic scheduling. Yi Jianqi et al [2] established the simulation model of the port tugboat operating system in two operation modes of single parking base and multi-parking base respectively, and studied the tugboat configuration in different situations. Yang Zhihua [3] using simulation technology derived tugboat utilization and port performance under different configuration options. Zhang Peng[4], Liu Zhixiong [5] set up a simulation model to restore the whole process of tugboat operations in port. Su [6] use simulation software ARENA to look into the harbor tugboat operation, and also use performance indicator to evaluate the harbor tugboat utilization, effectiveness of man power scheduling and the waiting status of the ships. Vu [7] presents an optimal power management scheme for an electromechanical marine vessel's powertrain, and also proposed an optimization algorithm which can schedule the operation, i.e., starting time and stopping time for a multiengine configuration optimally, which is a key difference from the previously developed optimal power management algorithms for landbased hybrid electric vehicles. Jung $\mathrm{C} \mathrm{H}$ et al [8] make a comparison of tugboat requirements among Korea major ports, proposed a criteria of tugboat requirement and method for calculation. Liu Z [9] applied a multiprocessor tasks scheduling theory to analyze the tugboat operation scheduling problem, which have been effectively improved tugboat utilization factor and reduced the waiting time of vessels

However, all the studies above took the tugboat scheduling as the planning target, and did not consider the situation of the tugboat configuration in the cases of different throughput capacity of the port. In this paper, a simulation model of the ship entering and leaving the port is established by the simulation software Arena. The quantity of tugboats that need to be configured at different guaranteed rates and different scale of ports is simulated to provide a basis for the reasonable configuration of tugboats and improve the operational efficiency of the port.

\section{PROBLEM DESCRIPTION}

\section{A. Related Concepts}

The harbor basin refers to the water within the harbor for the anchorage, operation, departure and turnaround of ships. Combined with the characteristics of the port channel and drawing on the definition of Hydraulic Engineering, the guarantee rate of the number of tugboats in the coastal port is defined as the cumulative frequency at which the number of tugboats in port reaches and is less than a certain value in a long time. For instance, the guarantee rate of 9 tugboat operations at the port is $97.10 \%$, which means that the cumulative frequency of not more than 9 tugs operating in port for a long period of time is $97.10 \%$.Maintaining the Integrity of the Specifications

The template is used to format your paper and style the text. All margins, column widths, line spaces, and text fonts are prescribed; please do not alter them. You may note peculiarities. For example, the head margin in this template measures proportionately more than is customary. This measurement and others are deliberate, using specifications that anticipate your paper as one part of the entire proceedings, and not as an independent document. Please do not revise any of the current designations.

\section{B. Port Tugboat Operation Process}

The main four steps required for a tugboat to operate when a ship enters the port and leaves the port: 
Arrival process: When the ship reaches the harbor channel, the ship needs to be towed to the berth for loading and unloading operations by tugboat.

Moving process: When there are many types of loading and unloading cargo, it is necessary to carry out tugs at multiple terminals. Since the vessels can not move between different wharves by themselves, tugboat-assisted work is required.

The ship turned around: Depending on the setting of maneuvering waters and berths in different port areas, some ships may need to turn their heads to complete their work when entering or leaving the port. In this case, tugboat-assisted work is required.

Leave the port process: After completing the work at the port, the ship needs to leave the berth to enter the waterway with the help of a tugboat.

\section{Ship to Departure Operations}

Ships to departure operations as shown in Figure I. When the depth of the basin is sufficient, when the width of the basin is less than a certain critical value. The ship can only sail one way in the port and need to make a U-turn operation outside the port. As the width of the harbor tank increases, some tonnage vessels can make two-way navigation and allow a U-turn in the harbor. The greater the width of the harbor basin, the larger the tonnage and size of ships that allow two-way navigation and U-turn, resulting in the greater number of tugs required.

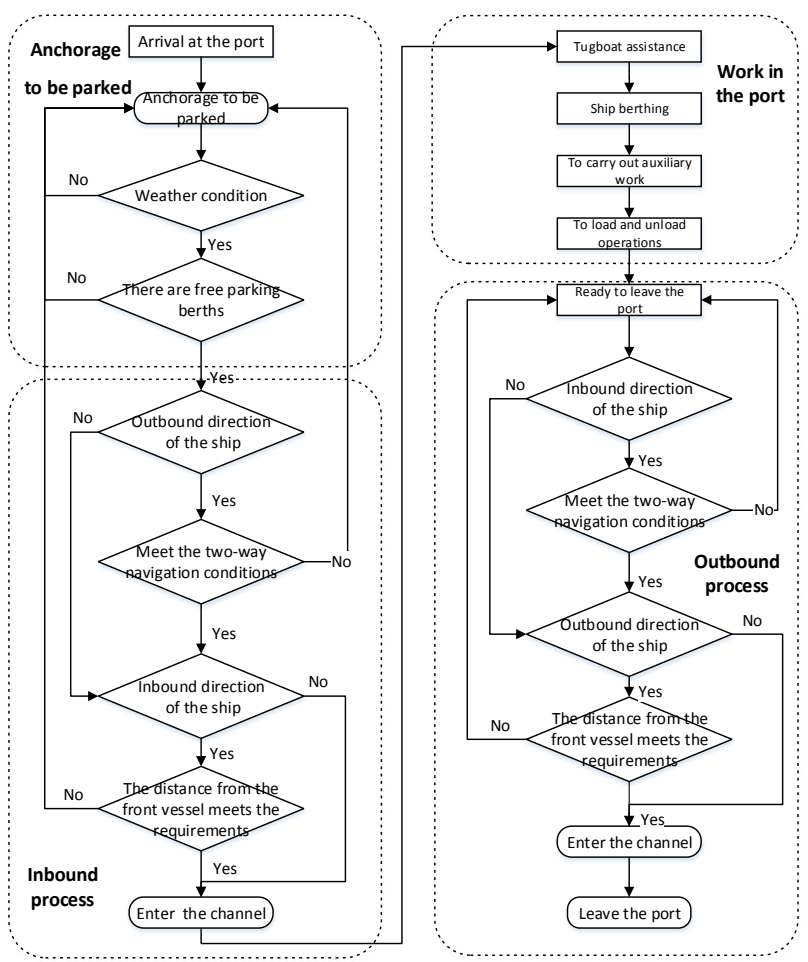

FIGURE I. SHIP TO DEPARTURE OPERATION FLOW

\section{Simulation Model Construction}

\section{A. Basic Assumptions}

Depending on the setting of maneuvering waters and berths in different port areas, some ships may need to turn their heads to complete their work when entering or leaving the port. In this case, tugboat-assisted work is required.

During the navigation period, weather conditions in port have a stable impact and do not show extremely bad weather.

The port operated in good condition and all-tonnage ships maintained steady speed while navigating.

The harbor has a large enough anchorage to provide a waiting service for the ship.

Handling system work properly, handling efficiency is stability.

\section{B. Ship to Departure Operation System Simulation Mode2l}

Ship to departure operation system is a complex discrete event system with obviously Random and dynamic. Therefore, this article uses simulation software Arena component simulation model, the model mainly includes anchorage to berth, the ship into the port, the port operation and the departure of the ship and other sub-models, shown in Figure II

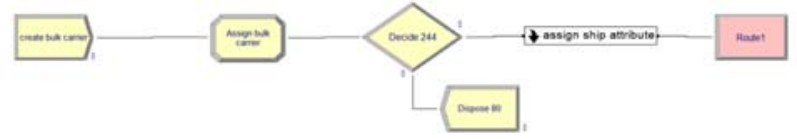

a) Anchorage berth to be sub-model

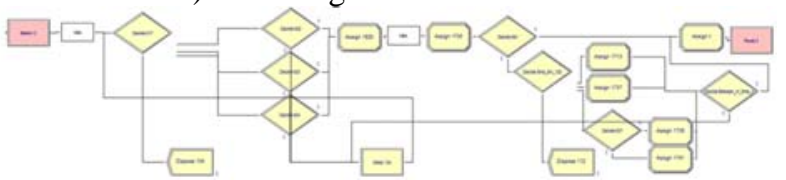

b) Ships into port sub model

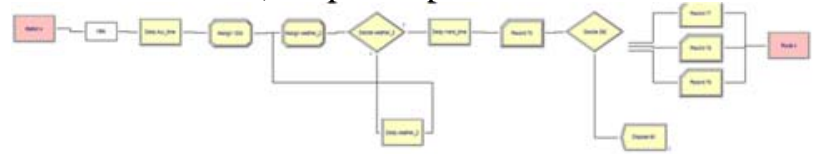

c) Sub-model of operation in port

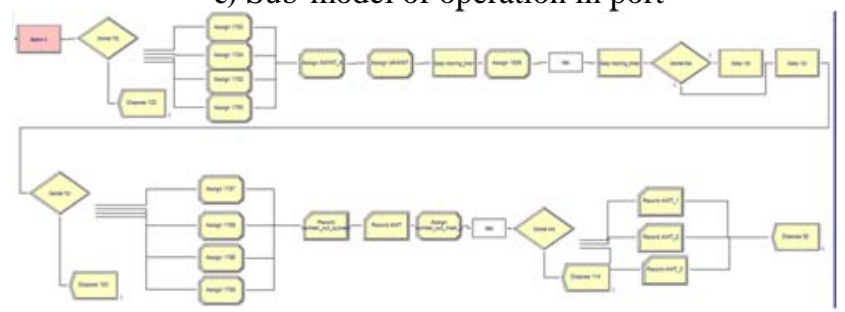

d) Ship departure sub-model

FIGURE II. SHIP IN AND OUT OF THE PORT OPERATING SYSTEM SIMULATION MODEL

Ships into port sub model: Create module generate the ship entity, and in the subsequent assignment module on the ship tonnage, speed, loading and unloading and a series of parameters assigned; then through the "weather conditions" module, the "VBA" module Pointing to complete the process, ready to enter the fairway.

Anchorage to be parked model: The vessel firstly determines whether the tidal range condition, the waterway condition and the safety time span are satisfied after determining by the tonnage judgment module whether the current harbor width satisfies the two-way navigation and then confirms the tide 
condition, the navigation condition and the safety time span after passing the judgment of "safe time zone judgment module" and "tide condition judgment", The ship enters the waterway. After the passage of time, leave the fairway

Operational sub-model in port: The ship enters the harbor basin and the U-turn module is used to make a U-turn, and then the tugboat completes berthing. Subsequent "auxiliary operations", "loading and unloading operations" sub-module berth loading and unloading operations.

Ship departure sub-model: The main flow and the ship into the port module the same, not repeat them here.

\section{EXAMPLE ANALYSIS}

Taking a foreign coastal port area to be constructed as an example, the change of tugboat quantity under each guarantee rate is analyzed when throughout capacity is different. The layout of the port area is shown in Figure III.

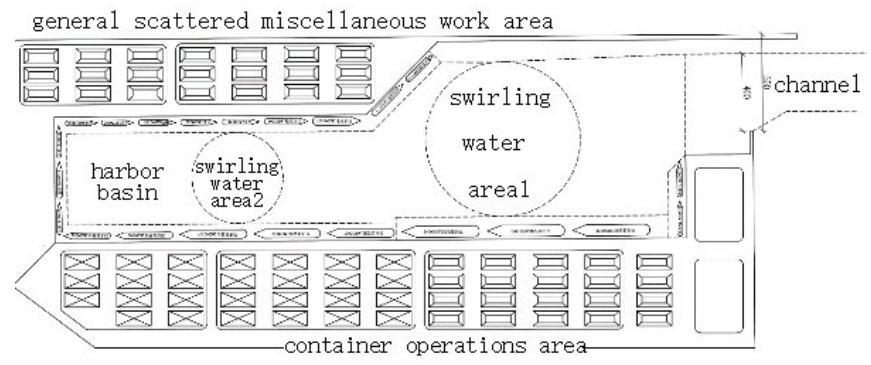

FIGURE III. PORT AREA LAYOUT PLAN

\section{A. Simulation Parameters}

\section{1) Arrival ships}

The ship arrival time interval obeys negative exponential distribution. The arriving ships are divided into general cargo ships, bulk carriers and container ships, accounting for $6.0 \%$, $30.5 \%$ and $63.5 \%$ respectively. The minimum tonnage of ships is 0.5 tonnage and the maximum is the 200,000-ton class and auxiliary operation time are $3 \mathrm{~h}, 5 \mathrm{~h}$ and $4 \mathrm{~h}$ respectively. The loading and unloading capacity of bulk groceries is 2500-73000t in the port and 300-4000TEU in container ships.

2) Quantity of tugboat

The number of tugboat auxiliary operations required for each tonnage of ships is shown in Table 1.

TABLE I. TUGBOATS FOR EACH TONNAGE REQUIRED

\begin{tabular}{cc}
\hline Ships tonnage & $\begin{array}{c}\text { The number of tugs required } \\
\text { (ship) }\end{array}$ \\
\hline $1-2$ 万 $t$ & 2 \\
\hline $4-8$ 万 $t$ & 3 \\
\hline $10-20$ 万 $t$ & 4
\end{tabular}

3) Sailing speed

The navigation speed of the ship in the waterway is 0.84 knots $(1.55 \mathrm{~km} / \mathrm{h})$ and the tugboat towing speed is 0.53 knots $(1 \mathrm{~km} / \mathrm{h})$.

\section{4) Berth}

The berthing method of the ship is flexible berthing. If the length of the free coastline meets the requirement of anchoring a ship, the berthing operation of the ship is allowed. The length of shoreline required by the ship is determined by the master. The length of the general berth is $2760 \mathrm{~m}$ and that of the container berth is $3550 \mathrm{~m}$.

\section{5) Other parameters setting}

Tugboat towing speed of $1 \mathrm{~km} / \mathrm{h}$, the transfer time of the ship is $10 \mathrm{~min}$ for ships below $100,000 \mathrm{t}, 20 \mathrm{~min}$ for ships of $100000 t$ and above, and 10min for safe sailing of same-direction ships.

\section{B. Simulation Results Analysis}

Set the simulation duration is 12 months, run the model 50 times, take 50 times the average of the results of the operation as the output indicator. In the various types of ships to the same proportion of vessels under the premise of changing the number of ships to be ported to statistics under different capacity through the port required configuration tugboat number, with a guarantee rate of $95 \%$ as an example, the results shown in Figure 4 shows.

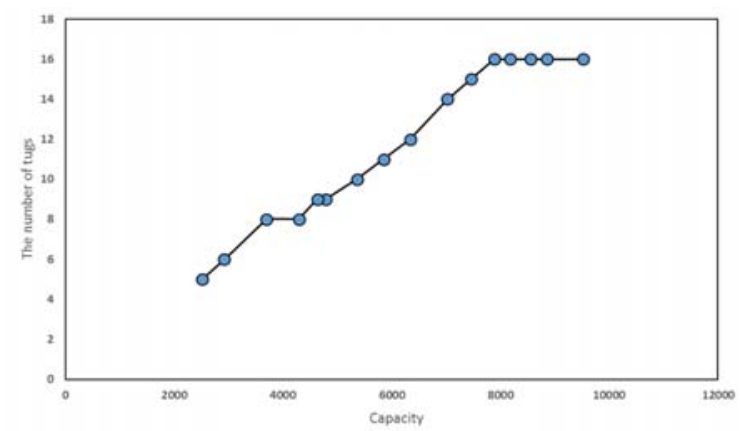

FIGURE IV. THE TACTILE NUMBER REQUIRED WHEN THE GUARANTEED RATE IS 95\% FOR DIFFERENT CAPACITY

As can be seen from Figure 4, with the increase of port throughput capacity, the number of tugboats to be deployed in the port area also increases. This shows that the increase in the quantity of ships arriving in port brings higher requirements for tugboat configuration in this port area. When the passage throughput capacity of the port area reached 78.84 million tons, the quantity of tugboats in the port area remained unchanged even though the number of vessels arriving in the port continued to increase, indicating that the configuration of the port area tugboats did not affect the port passage at this time Capacity is a key factor in the continued deployment of tugboats cannot enhance the port's ability to pass.

\section{CONCLUSION}

Tugboat operation is an indispensable part of the port production operation system, and the configuration of the tugboat is an important factor affecting the port throughput capacity. In this paper, by establishing the simulation model of the ship entering and leaving the port, this paper analyzes the quantity of tugboats required for different throughput capacity and draws the following conclusions:

- With the increase of the number of ships arriving in the port and the continuous improvement of the throughput capacity of the port, the quantity of tugboats required is also continuously increasing.

- When the throughput of the port area reaches 78.84 
million tons, the configuration of tugboats no longer has an obvious effect on the port throughput capacity.

\section{ACKNOWLEDGMENT}

The authors would like to acknowledge the support of National Natural Science Foundation of China (No. 51709037 and 51779037).

\section{REFERENCES}

[1] Dong liangcai, "The Dynamic Tugboat Schedule Based on Particle Swarm Algorithm Combined with Genetic Operators,” .

[2] Yi jianqi,Liu zhixiong,Cai ruidong, "Simulation and Decision of Port Tugboat Operation Configuration for Multi - parking Base,” [J]. 2015,(19): 105-109.

[3] Yangzhihua, "Simulation Research and Application of Port Tugboat Overall Configuration,”.Wuhan University of Technology,2003.

[4] Zhang Peng, "Tugboat Assisted Ship Modeling and Simulation. Dalian Maritime University,” Dalian Maritime University.2008.

[5] Liu zhixiong, Wang shaomei, "The Computer Simulation Study of Port Tugboat Operation,” Journal of System Simulation [J]. 2004, (01): 45-47.

[6] Su Y S. Simulation analysis for harbor tugboat operations: a case study for Port of Kaohsiung[J].

[7] Vu T L, Ayu A A, Dhupia J S, et al. Power Management for Electric Tugboats Through Operating Load Estimation[J]. IEEE Transactions on Control Systems Technology, 2015, 23(6):2375-2382.

[8] Jung C H, Kong G Y, Lee Y S. A Study on the Criteria of Tugboat Requirement in Domestic Trading Ports[J]. 2010, 16(1):1799-1805.

[9] Liu Z. Port tugboat operation scheduling optimization considering the minimum operation distance[J]. Journal of Southwest Jiaotong University, 2011, 46(5):875-881. 